Мельник B.A.

Гомельский государственный медицинский университет, 246000, ул. Ланге, 5, Гомель, Республика Беларусь

\title{
ТИПОЛОГИЧЕСКИЕ ОСОБЕННОСТИ РАЗВИТИЯ ВТОРИЧНЫХ ПОЛОВЫХ ПРИЗНАКОВ У ГОРОДСКИХ ДЕВОЧЕК-ПОДРОСТКОВ
}

Введение. Развитие вторичных половых признаков является одним из самых заметных морфологических изменений в период полового созревания. При этом в настоящее время существует мало научных работ, уточняющих последовательность и время достижения определенных стадий развития вторичных половых признаков у представителей различных соматотипов.

Материал и методы. В статье представлены результаты исследования развития вторичных половых признаков у 1757 городских девочек различных типов телосложения, обследованных в 2010-2012 ге. Стадии выраженности вторичных половых признаков определялись визуально по схеме Таннера. Программа исследования уровня полового созревания подростков включала изучение развития следующих вторичных половых признаков: степень оволосения лобка, подмышечных впадин и развитие молочных желез. Фиксировались данные о времени появления теnarche. Оценка степени развития вторичных половых признаков девочек осуществлена с учетом их соматотипа. Определение типа телосложения выполнялось по новой количественной схеме, разработанной и внедренной в практическую деятельность группой белорусских ученых.

Результаты и обсуждение. В результате проведенных исследований установлено, что первые стадии развития вторичных половых признаков у городских девочек статистически значимо раньше начинают проявляться у индивидов с гиперсомными вариантами телосложения (адипозным гиперсомным, гиперсомным). Однако несмотря на более поздние сроки проявления первой стадии развития вторичных половых признаков у обследуемых девочек с лептосомными соматотипами (астенизированный лептосомный и лептосомный), представительницы этих типов телосложения за счет более высоких темпов своего развития достигают дефинитивных стадий в те же сроки, что и девочки иных соматотипов. Наиболее раннее появление тепаrche выявлено у обследованных девочек с адипозным гиперсомным и гиперсомным соматототипами. Средний возраст появления теnarche, вычисленный ретроспективным методом, составил 12 лет 6 месяцев. Сроки и темпы развития вторичных половых признаков у городских девочек зависят от типа телосложения.

Ключевые слова: ауксология, вторичные половые признаки; девочки-подростки; соматотип, беларусы

\section{Введение}

Подростковый возраст, являясь одним из критических периодов онтогенеза, чрезвычайно важен в физиологическом, психологическом, нравственном и социальном становлении человека [Баранов, Щеплягина, 2006]. Именно в этот момент завершается формирование основных морфологических и функциональных структур организма, под влиянием половых гормонов происходит нейроэндокринная перестройка, заметно меняется тонус вегетативной нервной системы, интенсивно протекают процессы роста и развития, в результате чего реализуется индивидуальная генетически детерминированная программа развития организма [Баранов, Щеплягина, 2006; Chen et al., 2014; Utriainen et al., 2015].

Процесс полового созревания продолжается в среднем от 4 до 5 лет. При этом сроки могут изменяться с учетом воздействия различных внешних и внутренних фракторов [Тулякова, ЮрчукЗуляр, 2017]. Вторичные половые признаки, являясь индикатором полового созревания, отражают функциональный уровень развития орга- 
низма [Узунова с соавт., 2014; Филатова, Харченко, 2015].

Постоянный мониторинг темпов и сроков развития вторичных половых признаков необходим для выявления проблем состояния здоровья подрастающего поколения, так как во многих странах отмечаются тенденции к изменению сроков наступления пубертатного периода [Кучма с соавт., 2012; Деев с соавт., 2017; Boyne et al., 2010].

Несмотря на то, что развитие вторичных половых признаков - одно из самых заметных морфологических изменений в период полового созревания, существует относительно немного исследований, уточняющих последовательность и время достижения определенных стадий у представителей различных типов телосложения. В доступной литературе имеются научные работы, посвященные изучению полового созревания школьников, проживающих в условиях разной антропогенной нагрузки [Беляева с соавт., 2016], в сельской и городской местности [Михайлова, 2015; Кучма с соавт., 2012], также установлены связи размеров тела с процессами полового созревания [Федотова, Чтецов, 2013].

Цель работы - изучить сроки и темпы развития вторичных половых признаков у городских девочек в зависимости от типа телосложения.

\section{Материал и методы}

В период 2010-2012 гг. проведено комплексное морфофункциональное обследование 1757 девочек средних образовательных школ г. Гомеля в возрасте от 7 до 17 лет, не имеющих существенных отклонений в состоянии здоровья (I и II группы здоровья). В исследованной выборке преобладали белорусы, которые родились и выросли в г. Гомеле и оба родителя которых являлись белорусами (92,2\%). Меньшую долю составили обследованные, у которых один из родителей белорус, второй - русский либо украинец. Программа исследования уровня полового созревания подростков включала изучение развития следующих вторичных половых признаков: степень оволосения лобка $(P)$, подмышечных впадин $(A x)$ и развитие молочных желез (Ма). Фиксировались данные о времени появления menarche (Me). Стадии выраженности вторичных половых признаков определялись визуально по схеме Таннера [Tanner, 1962].

С целью избегания возможных проблем, связанных со сбором данных о половом созревании девочек, оценка стадий выраженности развития вторичных половых признаков выполнялась к.м.н., доцентом кафедры педиатрии УО «Гомельский государственный медицинский университет» А.А. Козловским. Все исследования проводились с письменного согласия родителей, разрешения Управления здравоохранения Гомельского областного исполнительного комитета, а также на основании заключенных договоров о сотрудничестве между УО «Гомельский государственный медицинский университет» и средними образовательными школами г. Гомеля.

Определение соматотипической принадлежности осуществлялось по новой количественной схеме «Способ количественной оценки типов телосложения по комплексу антропометрических показателей», разработанной и внедренной в практическую деятельность группой белорусских ученых И.И. Саливон, Н.И Полиной и В.А. Мельником [Мельник, Саливон, 2013]. Методика предусматривает выделение трех основных вариантов телосложения (соматотипов): астенизированного лептосомного (АстЛ), мезосомного (М) и адипозного гиперсомного (АдГ), а также четырех переходных - лептосомного (Л), мезолептосомного (МЛ), мезогиперсомного (МГ) и гиперсомного (Г).

В исследовании после определения типа телосложения обследуемые были распределены по подгруппам в зависимости от конституциональных особенностей телосложения. Оценка стадий развития вторичных половых признаков осуществлена с учетом соматотипа.

Учитывая имеющиеся расхождения в методиках определения типа телосложения, предложенной авторами статьи (количественный метод) и другими исследователями (визуальные методы), проведение сравнительного анализа наших данных с материалами других исследователей не выполнялось.

Статистическая обработка осуществлялась с использованием пакета прикладных статических программ «STATISTICA 7.0». Полученные результаты представлены в виде средних арифрметических величин (M) и стандартного отклонения (SD). Гипотеза о нормальном распределении величин проверена с помощью критерия Шапиро-Уилка. Значимость различий оценивалась по критерию Манна-Уитни (U-критерий). Результаты анализа считались статистически значимыми при р<0,05.

\section{Результаты и обсуждение}

В оценке полового созревания девочек большую роль играет возраст menarche. Сопоставление
АНТРОПОЛОГИЯ № 3/2018: 90-95 Anthropology, 2018, no. 3, pp. 90-95
Вестник Московского университета. Серия ХХIII Moscow University Anthropology Bulletin 
Таблица 1. Динамика развития стадий вторичных половых признаков (лет) у девочек-школьниц в зависимости от типа телосложения

Table 1. Development of secondary sexual characteristics stages (years) in school girls depending on their body type

\begin{tabular}{|c|c|c|c|c|c|c|c|}
\hline \multirow{2}{*}{$\begin{array}{l}\text { Период } \\
\text { развития } \\
\text { признака }\end{array}$} & \multicolumn{7}{|c|}{ Тип телосложения } \\
\hline & АстЛ & Л & МЛ & M & МГ & $\Gamma$ & АдГ \\
\hline $\mathrm{Ma}_{1}-\mathrm{Ma}_{2}$ & $\begin{array}{c}1 \text { год } \\
8,6 \text { мес. }\end{array}$ & $\begin{array}{c}1 \text { год } \\
0,2 \text { мес. }\end{array}$ & 11,0 мес. & $\begin{array}{c}1 \text { год } \\
3,6 \text { мес. }\end{array}$ & $\begin{array}{c}1 \text { год } \\
4,5 \text { мес. }\end{array}$ & $\begin{array}{c}1 \text { год } \\
8,2 \text { мес. }\end{array}$ & $\begin{array}{c}2 \text { года } \\
0,5 \text { мес. }\end{array}$ \\
\hline $\mathrm{Ma}_{2}-\mathrm{Ma}_{3}$ & 8,4 мес. & $\begin{array}{c}1 \text { год } \\
5,4 \mathrm{мес} .\end{array}$ & $\begin{array}{c}1 \text { год } \\
1,0 \text { мес. }\end{array}$ & $\begin{array}{c}1 \text { год } \\
5,1 \mathrm{мес.}\end{array}$ & $\begin{array}{c}1 \text { год } \\
7,0 \text { мес. }\end{array}$ & $\begin{array}{c}1 \text { год } \\
8,6 \text { мес. }\end{array}$ & 11,2 мес. \\
\hline $\mathrm{Ma}_{3}-\mathrm{Ma}_{4}$ & $\begin{array}{c}1 \text { год } \\
8,1 \text { мес. }\end{array}$ & $\begin{array}{c}1 \text { год } \\
7,5 \text { мес. }\end{array}$ & $\begin{array}{c}1 \text { год } \\
10,0 \text { мес. }\end{array}$ & $\begin{array}{r}2 \text { года } \\
0,3 \text { мес. }\end{array}$ & $\begin{array}{r}2 \text { года } \\
2,5 \text { мес. }\end{array}$ & $\begin{array}{c}1 \text { год } \\
9,0 \text { мес. }\end{array}$ & $\begin{array}{c}1 \text { год } \\
8,1 \text { мес. }\end{array}$ \\
\hline$M a_{1}-M a_{4}$ & $\begin{array}{c}4 \text { года } \\
1,1 \text { мес. }\end{array}$ & $\begin{array}{c}4 \text { года } \\
1,1 \text { мес. }\end{array}$ & $\begin{array}{c}3 \text { года } \\
10,0 \text { мес. }\end{array}$ & $\begin{array}{c}4 \text { года } \\
9,0 \text { мес. }\end{array}$ & $\begin{array}{c}5 \text { лет } \\
2,0 \text { мес. }\end{array}$ & $\begin{array}{c}5 \text { лет } \\
1,8 \text { мес. }\end{array}$ & $\begin{array}{c}4 \text { года } \\
7,8 \text { мес. }\end{array}$ \\
\hline$P_{1}-P_{2}$ & $\begin{array}{c}1 \text { год } \\
2,3 \text { мес. }\end{array}$ & $\begin{array}{c}1 \text { год } \\
0,8 \text { мес. }\end{array}$ & $\begin{array}{c}1 \text { год } \\
0,2 \text { мес. }\end{array}$ & 8,4 мес. & 10,8 мес. & $\begin{array}{c}1 \text { год } \\
2,1 \text { мес. }\end{array}$ & 10,4 мес. \\
\hline $\mathrm{P}_{2}-\mathrm{P}_{3}$ & $\begin{array}{c}1 \text { года } \\
3,0 \text { мес. }\end{array}$ & $\begin{array}{c}2 \text { года } \\
5,5 \text { мес. }\end{array}$ & $\begin{array}{c}1 \text { год } \\
11,3 \mathrm{меc.}\end{array}$ & $\begin{array}{r}2 \text { года } \\
8,8 \text { мес. }\end{array}$ & $\begin{array}{c}2 \text { года } \\
9,9 \text { мес. }\end{array}$ & $\begin{array}{r}2 \text { года } \\
8,7 \text { мес. }\end{array}$ & $\begin{array}{r}2 \text { года } \\
1,5 \text { мес. }\end{array}$ \\
\hline $\mathbf{P}_{1}-\mathbf{P}_{3}$ & $\begin{array}{r}2 \text { года } \\
5,3 \text { мес. }\end{array}$ & $\begin{array}{c}3 \text { года } \\
\text { 6,3 мес. }\end{array}$ & $\begin{array}{c}2 \text { года } \\
11,5 \text { мес. }\end{array}$ & $\begin{array}{c}3 \text { года } \\
5,2 \text { мес. }\end{array}$ & $\begin{array}{c}3 \text { года } \\
8,7 \text { мес. }\end{array}$ & $\begin{array}{c}3 \text { года } \\
10,8 \text { мес. }\end{array}$ & $\begin{array}{c}2 \text { года } \\
11,9 \text { мес. }\end{array}$ \\
\hline$A x_{1}-\mathrm{Ax}_{2}$ & $\begin{array}{c}1 \text { год } \\
4,3 \text { мес. }\end{array}$ & 11,8 мес. & $\begin{array}{c}1 \text { год } \\
1,5 \mathrm{мес.}\end{array}$ & $\begin{array}{c}1 \text { год } \\
6,5 \mathrm{мес.}\end{array}$ & $\begin{array}{c}1 \text { год } \\
5,7 \text { мес. }\end{array}$ & $\begin{array}{c}1 \text { год } \\
9,1 \mathrm{мес.}\end{array}$ & $\begin{array}{c}1 \text { год } \\
5,6 \mathrm{мес} .\end{array}$ \\
\hline $\mathrm{Ax}_{2}-\mathrm{Ax}_{3}$ & $\begin{array}{r}2 \text { года } \\
3,7 \text { мес. }\end{array}$ & $\begin{array}{c}1 \text { год } \\
4,2 \text { мес. }\end{array}$ & $\begin{array}{c}1 \text { год } \\
11,9 \text { мес.. }\end{array}$ & $\begin{array}{c}1 \text { год } \\
8,9 \text { мес. }\end{array}$ & $\begin{array}{c}2 \text { года } \\
3,9 \text { мес. }\end{array}$ & $\begin{array}{c}1 \text { год } \\
9,3 \text { мес. }\end{array}$ & $\begin{array}{c}1 \text { год } \\
8,1 \text { мес. }\end{array}$ \\
\hline $\mathbf{A} \mathbf{x}_{1}-\mathbf{A} \mathbf{x}_{3}$ & $\begin{array}{c}3 \text { года } \\
8,0 \text { мес. }\end{array}$ & $\begin{array}{c}2 \text { года } \\
4,0 \text { мес. }\end{array}$ & $\begin{array}{c}3 \text { года } \\
1,4 \text { мес. }\end{array}$ & $\begin{array}{c}3 \text { года } \\
3,4 \text { мес. }\end{array}$ & $\begin{array}{c}3 \text { года } \\
\text { 9,6 мес. }\end{array}$ & $\begin{array}{c}3 \text { года } \\
6,4 \text { мес. }\end{array}$ & $\begin{array}{c}3 \text { года } \\
1,7 \text { мес. }\end{array}$ \\
\hline
\end{tabular}

Примечания. Тип телосложения: АстЛ - астенизированный лептосомный; Л - лептосомный; МЛ-мезолептосомный; М - мезосомный; МГ - мезогиперсомный; Г- гиперсомный; АдГ - адипозный гиперсомный.

Notes. Somatotype: AstL - asthenized leptosomic; L - leptosomic; ML - mezoleptosomic; M - mezosomic; $\mathrm{MH}$ - mezohypersomic; $\mathrm{H}$ - hypersomic; $\mathrm{AdH}$ - adipose hypersomic.

распределения частоты встречаемости девочек с Ме в зависимости от типов телосложения показало, что наиболее раннее статистически значимое ( $p<0,005-0,001)$ появление признака, по сравнению с другими типами телосложения, выявлено у девочек с адипозным гиперсомным (12,06 \pm 1,09 лет) и гиперсомным $(12,30 \pm 1,19$ лет) соматотипами.

Самые поздние сроки появления Ме установлены среди девочек мезолептосомного и мезогиперсомного телосложения (14,93 \pm 1,48 и 14,93 \pm 1,61 лет). Таким образом, у девочек с адипозным гиперсомным соматотипом Ме появляется на 2,87 года раньше по сравнению с мезолептосомными и мезогиперсомными девочками (табл. 1).

Вместе c menarche достаточно информативным признаком полового созревания у девочек является развитие молочных желез. В результате проведенного анализа полученных данных установлено, что первая стадия развития молочных желез $\left(\mathrm{Ma}_{1}\right)$ статистически значимо раньше ( $<<0,02-0,001)$ начала проявляться у девочек с гиперсомным (9,72 $\pm 1,17$ лет) и адипозным гипер- сомным соматотипами $(9,80 \pm 1,10$ лет) по сравнению со школьницами других типов телосложения. Среди девочек с лептосомным и астенизированным лептосомным типом $\mathrm{Ma}_{1}$ выявлялась позже других $(11,70 \pm 1,37$ и 11,48 \pm 1,08 лет соответственно). Следовательно, у девочек гиперсомного соматотипа по сравнению с лептосомным стадия Ма, появлялась почти на 2 года раньше.

В процессе развития молочных желез до дефинитивной стадии отмечена тенденция к сокращению сроков появления стадий $\mathrm{Ma}_{2}$ и $\mathrm{Ma}_{3}$ среди девочек, у которых $\mathrm{Ma}_{1}$ проявилась позже. В частности, появление стадии $\mathrm{Ma}_{2}$ у девочек гиперсомного телосложения установлено через 1,82 года, стадии $\mathrm{Ma}_{3}$ - через 1,86 года, а стадии $\mathrm{Ma}_{4}$ - через 1,9 года. При этом девочки с лептосомным соматотипом, у которых стадия Ма, появилась позже всех, достигали дефинитивной стадии развития признака за более короткий период времени (табл. 1).

Таким образом, имеющиеся значимые различия ( $<<0,02-0,001)$ по срокам появления стадии $\mathrm{Ma}_{1}$ между школьницами различных соматотипов 
исчезают к моменту развития дефинитивной стадии признака (за исключением крайних, т.е. противоположных типов телосложения, например астенизированного лептосомного и адипозного гиперсомного).

После начала пубертатных изменений молочных желез начинают появляться волосы на лобке. В исследуемой выборке первая стадия оволосения лобка $\left(\mathrm{P}_{1}\right)$ раньше всего проявлялась у девочек с адипозным гиперсомным и гиперсомным соматотипами $(10,82 \pm 0,58$ лет и 10,65 \pm 0,89 лет соответственно).

Статистически значимо позже ( $p<0,01-0,007)$ стадия $\mathrm{P}_{1}$ отмечалась среди девочек с астенизированным лептосомным типом телосложения (12,22 \pm 0,86 лет) по сравнению со школьницами других соматотипов (кроме лептосомного и мезолептосомного вариантов). Девочки с астенизированным лептосомным типом телосложения достигали дефинитивной стадии развития признака за 2 года 5,3 месяца, а девочки с адипозным гиперсомным и гиперсомным соматотипами за 3 года 10,8 месяца и 2 года 11,9 месяца соответственно (табл. 1).

Из исследованных нами признаков полового созревания у девочек наиболее поздним является оволосение подмышечных ямок (Ax). У обследуемых первая стадия этого признака раньше всего статистически значимо ( $p<0,01-0,007)$ по сравнению со школьницами других соматотипов проявлялась у девочек с адипозным гиперсомным и гиперсомным соматотипами $(11,64 \pm 0,91$ лет и $11,68 \pm 1,15$ лет соответственно). Позже всего стадия $\mathrm{Ax}_{1}$ проявлялась среди девочек с лептосомным типом телосложения (13,38 \pm 1,22 лет). При этом девочки с данным соматотипом достигали дефинитивной стадии развития признака за 2 года 4,0 месяца, а девочки с адипозным гиперсомным и гиперсомным типами телосложения за 3 года 1,7 месяца и 3 года 6,4 месяца соответственно (табл. 1).

Более раннее начало развития вторичных половых признаков у девочек с повышенной массой тела вероятнее всего связано с функционированием жировой ткани как эндокринного органа и экстрагенитальной выработкой эстрогенов [Марков, Марков, 2016].

\section{Заключение}

Таким образом, анализ полученных данных свидетельствует о том, что сроки и темпы развития вторичных половых признаков у девочек зависят от индивидуального типа телосложения. Первые стадии развития вторичных половых признаков у городских девочек статистически значимо ( $p<0,05-0,001)$ раньше начинают проявляться у подростков с повышенным жироотложением, т.е. с гиперсомными вариантами телосложения (адипозным гиперсомным, гиперсомным). Однако несмотря на более поздние сроки проявления первой стадии развития вторичных половых признаков у обследуемых с лептосомными соматотипами (астенизированный лептосомный и лептосомный), представительницы этих типов телосложения за счет более высоких темпов их развития достигают дефинитивных стадий в те же сроки, что и девочки иных соматотипов.

Наиболее раннее появление menarche по сравнению с другими типами телосложения статистически значимо ( $<<0,005-0,001)$ отмечается у обследованных девочек с адипозным гиперсомным и гиперсомным соматототипами. Средний возраст появления menarche, вычисленный ретроспективным методом, составил 12 лет 6 месяцев.

\section{Благодарности}

Автор благодарит сотрудников кафедры педиатрии учреждения образования «Гомельский государственный медицинский университет» за помощь в проведении исследований.

\section{Библиография}

Баранов А.А., Щеплягина Л.А. Физиология роста и развития детей и подростков (теоретические и клинические вопросы). М.: ГЭОТАР-Медиа, 2006. 432 с.

Беляева А.В., Сливина Л.П., Латышевская Н.И., Давыденко Л.А., Шестопалова Е.Л. Особенности полового развития девочекподростков в условиях разной антропогенной нагрузки // Сибирский научный медицинский журнал, 2016. Т. 36. № 6. С. 99-102. Гланц С. Медико-биологическая статистика. М.: Практика, 1999. $462 \mathrm{c}$.

Деев И.А., Коломеец И.Л., Саприна Т.В., Кобякова О.С., Камалтынова Е.М. с соавт. Половое развитие подростков в Томской области // Педиатрическая фрармакология, 2017. Т. 14. № 5. C 366-372.

Кучма В.Р., Скоблина Н.А., Бокарева Н.А., Милушкина О.Ю. Особенности полового созревания современных московских школьников // Российский педиатрический журнал, 2012. № 6. C. 44-47.

Марков П., Марков Д. Метаболическая и гормональная активность жировой ткани - значение медицинской практики // Psychology. Educology. Medicine, 2016. № 1. C. 60-67.

Мельник В.А., Саливон И.И. Методика определения типов телосложения детского населения по комплексу антропометрических показателей. Учеб.-метод. пособие. Гомель: Изд-во ГомГМУ, 2013. 36 с. 
Михайлова С.В. Показатели полового созревания сельских школьников Нижегородской области // Морфология, 2015. T. 148. № 4. С. 37-42.

Тулякова О.В., Юрчук-Зуляр О.А. Состояние полового и физического развития девушек 13-14 лет в условиях аэротехногенного загрязнения // Новые исследования, 2017. № 1 (50). C. 78-84.

Узунова А.Н., Лопатина Д.А., Петрунина С.Ю., Шарапов А.Р., Харрасова E.X. Особенности взаимосвязи параметров фиизического и полового развития подростков Челябинска // Гигиена и санитария, 2014. Т. 93. № 4. С. 75-78.
Федотова Т.К., Чтецов В.П. Внутригрупповые связи изменчивости размеров тела с процессами полового созревания у детей школьного возраста // Вестник Московского университета. Серия XXIII. Антропология, 2013. № 3. С. 28-41.

Филатова О.В., Харченко Е.В. Особенности взаимосвязи параметров физического и полового развития подростков Барнаула // Acta Biologica Sibirica, 2015. T. 1. № 3-4. С. 7-23.

\section{Сведения об авторах}

Мельник Виктор Александрович, к.б.н., доцент, melnik76@tut.by.

Melnik V.A.

Gomel State Medical University, 5 Lange Street, Gomel, 246000, Republic of Belarus

\section{THE TYPOLOGICAL FEATURES OF DEVELOPMENT OF SECONDARY SEX CHARACTERISTICS IN CITY TEENAGE GIRLS}

Introduction. Development of secondary sex characteristics is one of the most noticeable morphological changes during puberty. At the same time very few scientific works are present that specify the order and time of reaching certain stages of development of sex characteristics in representatives of different somatotypes.

Material and methods. The article presents the results of the study of development of secondary sex characteristics in 1757 city girls with different body types examined over 2010-2012. The stages of secondary sex characteristics were determined visually according to J. M. Tanner's scale. Following secondary sex characteristics were studies: degree of pubic hair distribution, axillary hair distribution, and development of mammary glands. Data on menarche were recorded. Stage of secondary sex characteristics development of girls was assessed taking into account their somatotype. Body types were determined according to the new qualitative scheme developed and introduced into practice by a team of Belarusian scientists.

Results and discussion. As a result of the conducted study it has been found that the first stages of development of secondary sex characteristics in city teenage girls appear in those with hypersomic body types (adipose hypersomic, hypersomic) considerably earlier. However, despite the later start of development of secondary sex characteristics in girls with leptosomic somatotypes (asthenized leptosomic and leptosomic), representatives of these body types reach definitive stages within the same terms as girls with other somatotypes at the expense of higher rates of their development. Girls with adipose hypersomic and hypersomic somatotypes have the earliest menarche. The average age at menarche calculated by the retrospective method was 12.5 years. The timing and rates of secondary sex characteristics development in city teenage girls depend on their body types.

Keywords: auxology; secondary sex characteristics; teenage girls; somatotype; Belarusian 


\section{References}

Baranov A.A., Shcheplyagina L.A. Fiziologiya rosta i razvitiya detey i podrostkov (teoreticheskie $i$ klinicheskie voprosy) [Physiology of growth and development of children and adolescents (theoretical and clinical issues)]. Moscow: GEOTAR-Media Publ., 2006. 432 p. (In Russ).

Belyaeva A.B., Slivina L.P., Latyshevskaya N.I., Davydenko L.A., Shestopalova E.L. Osobennosti polovogo razvitiya devochekpodrostkov $v$ usloviyach raznoy antropogenennoy nagruzki [Pecularities of sexual development of adolescent girls in conditions of anthropological stress]. Sibirskiy meditsinkiy zhurnal [Siberian medical journal], 2016, 36 (6), pp. 99-102. (In Russ).

Glants S. Mediko-biologicheskaya statistika [Medico-biological statistics]. Moscow, Praktika Publ., 1999. 462 p. (In Russ.).

Deev I.A. Kolomnets I.L., Saprina T.V., Kobyakova O.S., Kamaltynova E.M. et al. Polovoe razvitie podrostkov v Tomskoy oblasti [Sexual development of adolescents in Tomsk Oblast]. Pediatricheskaya farmakologiya [Pediatric pharmacology], 2017, 14 (5), pp. 366-372. (In Russ).

Kuchma V.R. Skoblina N.A., Bokareva N.A., Milushkina O.Yu. Osobennosti polovogo sozrevaniya sovremennykh moskovskikh shkol'nikov [Features of puberty of modern Moscow schoolchildren]. Rossiiskiy pediatricheskii zhurnal [Russian Pediatric Journal], 2012 6. pp. 44-47. (In Russ).

Markov P., Markov D. Metabolicheskaya i gormonal'naya aktivnost' zhirovoi tkani - znachenie meditsinskoi praktiki [Metabolic and hormonal activity of adipose tissue - the importance of medical practice]. Psychology. Educology. Medicine, 2016, 1. pp. 60-67. (In Russ).

Mel'nik V.A., Salivon I.I. Metodika opredeleniya tipov teloslozhenia detskogo naseleniya po kompleksy antropometricheskich pokazaley: ycheb.-metod. posobie [Methods of body types identification of child population using a complex of anthropometric characteristics: study guide]. Gomel, Izd-vo GomGMU Publ., 2013. 36 p. (In Russ.).

Mihaylova S.V. Polazateli polovogo sozrevaniya sel'skih shkolnikov Nizhegorodskoy oblasti [Characteristics of sexual development of rural schoolchildren in Nizhny Novgorod Oblast]. Morfologiya [Morphology], 2015, 148 (4), pp. 37-42. (In Russ).
Tulyakova O.V., Yurchuk-Zulyar O.A. Sostoyanie polovogo i fizicheskogo razvitiya devushek 13-14 let $v$ usloviyah aerotehnogennogo zagryazneniya [Level of sexual and physical development of girls at the age of 13-14 in conditions of aerotechnogenic pollution]. Novye issledovaniya [New research], 2017, 1 (50), pp. 78-84. (In Russ).

Uzunova A.N., Lopatina D.A., Petrunina S.Yu., Sharapov A.R., Harrasova E.H. Osobennosti vzaimosvyazi parametrov fizicheskogo i polovogo razvitiya podrostkov Chelyabinska [Peculiarities of interrelation of physical and sexual development characteristics of adolescents in Chelyabinsk]. Gigiena $i$ sanitariya [Hygiene and sanitary], 2014, 93 (4), pp. 75-78. (In Russ).

Fedotova T.K., Chtetsov V.P. Vnutrigruppovye svyazi izmenchivosti razmerov tela s protsessami polovogo sozrevaniya u detei shkol'nogo vozrasta [Intra-group relationships of variability in body size with puberty processes in school-age children] // Vestnik Moskovskogo universiteta Seriya 23: Antropologiya [Moscow University Anthropology Bulletin], 2013, 3, pp. 28-41. (In Russ).

Filatova O.V., Harchenko E.V. Osobennosti vzaimosvyaz parametrov fizicheskogo i polovogo razvitiya podrostkov Barnaula [Peculiarities of interrelation of physical and sexual development characteristics of adolescents in Barnaul]. Acta Biologica Sibirica, 2015, 1 (3-4), pp. 7-23. (In Russ).

Tanner J.M. Growth at Adolescence. Oxford: Blackwell Sci. Publ., $1962 \mathrm{p}$.

Boyne M.S., Thame M., Osmond C. Growth, body composition, and the onset of puberty: longitudinal observations in Afro-Caribbean children. J. Clin. Endocrinol. Metab., 2010, 95 (7), pp. 3194-3200. DOI: 10.1210/jc.2010-0080.

Chen Y., Zhang Y.T., Chen C. Update on pubertal development among primary school students in Shanghai, 2014. Zhonghua $Y u$ Fang Yi Xue Za Zhi. 2016, 50 (11), pp. 971-975. DOI: 10.3760/ cma.j.issn.0253-9624.2016.11.010.

Utriainen P., Laakso S., Liimatta J. Premature adrenarche - a common condition with Variable presentation. Horm. Res. Paediatr, 2015, 83 (4), pp. 221-231. DOI: 10.1159/000369458.

\section{Authors' information}

Melnik Viktor A., PhD., associate professor, melnik76@tut.by. 